\title{
Examining the relationship between ethnicity and the use of drug-related services: an ethnographic study of Nepali drug users in Hong Kong
}

This article was published in the following Dove Press journal:

Substance Abuse and Rehabilitation

20 June 2014

Number of times this article has been viewed

\section{Wai-Man Tang}

Anthropology Department, The Chinese University of Hong Kong, Hong Kong
Correspondence: Wai-Man Tang Room 407, Humanities Building, New Asia College, The Chinese University of Hong Kong, Shatin, NT, Hong Kong

Tel 85293274034

Fax 85226035218

Emailwyman19@gmail.com
Abstract: A recent survey has shown that Nepali drug users in Hong Kong tend to have a low rate of usage of day-care and residential rehabilitation services, but a high rate of usage of methadone services. Little is known about the reasons behind such a pattern. Therefore, in this study, a 12-month ethnographic examination has been implemented in three sites, including a day-care center, residential rehabilitation center, and methadone clinic, to explore the experiences of 20 Nepali drug users in their use of drug-related services in Hong Kong and to examine the relationship between ethnicity and the use of drug-related services. The result shows that the reason for this pattern of service use is related to the approach of the services and the cultural perception of the service providers about the service users. The day-care and residential rehabilitation services emphasize an integrated approach, but the staff tend to overlook the heterogeneity of their clients, for example, the differences in caste and sex, and fail to provide suitable services to them, whereas the methadone service follows a biomedical model, which seldom addresses the social characteristics of the service users, which in turn minimizes the opportunity for misunderstandings between the staff and the clients. This research shows that ethnicity is a significant factor in drug treatment and that culture-specific treatment that takes into consideration the treatment approach and the heterogeneity of the clients is strongly needed.

Keywords: methadone, residential rehabilitation services, drug treatment, ethnicity, Nepalis

\section{Introduction}

According to the census, 63,176 South Asians resided in Hong Kong in 2011, making up $0.89 \%$ of the population. These South Asians were mostly Indians, Pakistanis, and Nepalis. The Narcotics Division in Hong Kong ${ }^{1}$ reported that there were 319 Nepali drug users in Hong Kong in 2012, most of whom (93.7\%) were heroin users. Among the non-Chinese drug users, Nepalis had the highest rate of drug use, making up $42.8 \%$ of the total number of drug users. Vietnamese (27.8\%), and Indians, Pakistanis, Bangladeshis, and Sri Lankans (16.2\%) helped make up the rest of the group. Compared with other Asian societies, Hong Kong has adopted a less punitive approach in its drug policy, ${ }^{2}$ and a wide variety of voluntary drug treatment and rehabilitation services are available. These drug-related services can be divided into two main types: residential and outpatient services. Outpatient services include methadone and substance abuse clinics and day-care centers. Residential rehabilitation and day-care services are mostly operated by nongovernmental organizations. Most of these organizations are affiliated with Christians and are administered by Hong Kong Chinese. Five of these organizations target current Nepali drug users. They emphasize that their services are "community-based" and "integrated," and they not only aim to help drug users 
quit the use of drugs but also assist them in reintegrating into society by liaising with their families and community. Comparatively, methadone services are operated by the Department of Health in Hong Kong. The services are lowthreshold and have high coverage..$^{3-5}$ Methadone clinics have been established throughout the territory, and there are few barriers to admission and retention in treatment. However, regulative practices, such as urinalysis and restrictive on-site doses, are implemented.

Research shows that both residential and outpatient drugrelated services in Hong Kong are highly regarded and used by local drug users. ${ }^{4,6}$ However, according to a survey of 89 Nepali drug users in Hong Kong, ${ }^{7}$ the respondents showed a pattern of treatment use: they have a relatively high usage rate of methadone services (74.2\%) and a relatively low usage rate of residential rehabilitation services $(27.0 \%)$. The aim of this research is thus to find out the views of Nepali heroin users on drug-related services in Hong Kong, explain why there is such a pattern of treatment use, and examine the effects of ethnicity on drug treatment.

Previous research has shown that residential treatment programs have no standard models, yet their treatment approach can be mainly divided into two types: psychopathology-based and faith-based. Although the former focuses on the observable conditions and behaviors of drug users, the latter focuses on the subjective experience of individuals and follows the positive psychology and social network support models. ${ }^{8}$ Many studies have found that these faith-based programs are effective forms of treatment for those with substance abuse disorders. For instance, recovering individuals who join faith-based programs tend to have a more optimistic life orientation, greater social support, greater resilience to stress, lower levels of anxiety, and higher levels of self-esteem. ${ }^{9-10}$ Similarly, recovering HIV-positive drug users who join faith-based programs are less likely to relapse or engage in HIV risk behavior, are more likely to follow medical recommendations, and have higher levels of hopefulness. ${ }^{11}$ Yet some studies have found that there is no correlation between participation in faith-based programs and addiction recovery. ${ }^{12-14}$

To account for the differences, some studies have suggested that there should be an operational definition for spirituality/religiosity. ${ }^{15,16}$ When drug users are matched to appropriate support groups or treatment programs according to their levels of spirituality/religiosity, their participation and treatment outcomes are enhanced. ${ }^{17}$ Furthermore, it has been noted in studies that the level of spirituality/religiosity of drug users correlates with their sociocultural backgrounds. ${ }^{11,18}$
For instance, women and ethnic minorities are found to have a higher level of spirituality/religiosity, and thus prefer a stronger emphasis on such in their treatment program. Residential rehabilitation treatment for ethnic minorities in Hong Kong is mostly operated by organizations affiliated with the Christian church, which uses religious intervention in its programs. Yet few Nepalis in Hong Kong believe in Christianity; they are Buddhists or Hinduists. This research attempts to determine whether religion-based programs are effective for ethnic minority drug users, especially when they hold different religious beliefs.

Methadone, a pharmacological agent used as a substitute treatment for illicit opioids, has proven to be effective in the treatment of opioid dependence. ${ }^{19,20}$ Furthermore, it can bring about positive social changes; for instance, reduction in crime rates and in the risk for transmission of blood-borne viruses such as HIV and hepatitis C. However, research has shown that its efficacy and intended positive social effects are not predetermined but are dependent on the sociocultural contexts of the methadone treatment. For instance, when methadone is defined as an addiction treatment, its delivery is usually restrictive and punitive. ${ }^{21-24}$ Users are monitored by various means, such as toxicology screening, restrictive on-site or take-away prescriptions, and frequent and inflexible appointments are situated in clinic spaces that resemble corrective service spaces. Furthermore, users are often stigmatized in the wider community. ${ }^{25,26}$ Methadone is negatively depicted in political and media circles. It is difficult for users to gain trust from their employers and acquire a stable job. As a consequence, opiate users are deterred from accessing and adhering to methadone services. Methadone treatment programs in Hong Kong also implement restrictive policies, such as urinalysis and restrictive on-site doses, and service users are stigmatized in the wider community. This research thus aims to determine how ethnic minorities, who already occupy a lower status in the social hierarchy, would evaluate methadone services, a social service that is low-threshold and effective but is also restrictive and stigmatizing.

Ethnicity, as a variable, is often examined in drug treatment studies, but there are no conclusive results. Some prior studies have reported that no relation is found between ethnicity and drug dependence or treatment outcome. ${ }^{27-29}$ On the contrary, some of the previous studies have found that drug users of different ethnic groups tend to have different levels of psychosocial functions, ${ }^{30}$ patterns of treatment use, ${ }^{31-34}$ and treatment outcomes. ${ }^{35-37}$ These studies used quantitative methods to collect their data and pointed out the differences, but they lack a holistic, cultural explanation to 
account for the differences. They often concluded that further investigation is needed to better understand the variations. In their recommendations, some of these studies suggested that culture-specific measures should be adopted in drug treatments; for instance, intensive cultural training for staff, employment of ethnically diverse staff, and provision of drug treatment information in a multitude of languages. ${ }^{30,33}$ Yet these studies tend to make essential the cultural differences of different ethnic groups without examining the cultural dynamics; for instance, how the social and cultural characteristics of different ethnic groups are formed and why the measures are relevant to particular sociocultural contexts. Migration studies on Nepali migrants have shown that the social compositions and cultural orientations of Nepali migrant communities are different in different places, such as India, Hong Kong, Japan, the United States, and the United Kingdom, and that these differences are often caused by different migration patterns and degrees of incorporation into the host society. ${ }^{38-45}$ This article discusses the patterns of treatment use of ethnic minorities by referring to the sociocultural-historical contexts of ethnic minorities, especially their migration history and interaction with local people in the host society.

This article also discusses the experiences of drug users in treatment programs and migration, and a qualitative research method (ie, ethnography) is used. No research has ever ethnographically studied overseas Nepali drug users, although much attention has been given to their situation in Nepal. Different reasons have been offered to explain their drug use; for instance, the traditional use of opium and marijuana in religious and medicinal contexts; ${ }^{46-49}$ Western influence, such as the hippie subculture in the $1960 \mathrm{~s},{ }^{50-52}$ and the changing political economy. ${ }^{53-54}$ However, their situation overseas is inadequately investigated. Thus, the findings of this study will address this issue and provide insights for policy makers and service providers to better serve this population.

\section{Methods}

The data in this research are derived from 12 months of participant observation in 2010 from three sites in Hong Kong, which included a residential rehabilitation center, a day-care center, and a methadone clinic. As this research aims to determine how religion and regulative practices in drug-related services influence the experience of ethnic minority drug users in drug treatment, a residential rehabilitation center and a day-care center that are operated by Christian organizations and a methadone center that is located near the Nepali community were selected. All of them specifically provide services for South Asians. With the help of the Beat Drugs Fund of the Hong Kong Narcotics Division, I received permission to carry out participation observation in these organizations, as well as interviews with individuals. Informants in this research are recruited by purposive sampling and snowball sampling. I first invited service providers to make referrals of individuals who were Nepali, had regularly used heroin in the past 3 months, had lived in Hong Kong for at least 3 months, and were currently using their services. Then I invited these informants to introduce their friends to me to obtain a larger sample. Furthermore, I continued to visit these organizations: the day-care center on a weekly basis for 4 months, the residential rehabilitation center biweekly and staying overnight for 6 months, and the methadone clinic twice a week for 2 months. While carrying out observations during the visits, I followed the situation of my informants through unstructured interviews.

A total of 20 informants participated in the interviews. They shared some common socioeconomic characteristics: all of them were young (20-35 years old at time of interview), migrated to Hong Kong when they were young (18-23 years old), and received their primary and secondary education in Nepal or India. Yet they also varied in terms of sex (two women and 18 men), ethnicity (eight Gurung, five Rai/Limbu, three Magar, two Damai, and two Kami), marital status (six married and 14 unmarried), birth place (nine in Hong Kong and eleven in Nepal), residence in Nepal (nine from Kathmandu, seven from Dharan, three from Pokhara, and one from Chitwan), and occupation in Hong Kong (nine worked as construction workers, eight as waiters/waitresses/ kitchen helpers/cleaners, and three as security guards). With regard to recruitment, ten were recruited from the methadone clinic, eight from the residential rehabilitation center, and two from the day-care center.

The interviews were semistructured and conducted in English. The interviews probed for information on individual drug use history, patterns of treatment use, reasons for using and/or terminating the service, effects of the service on drug use and daily life, and perspectives of transnational drug users of the service (eg, comparing drug-related services in Hong Kong and Nepal). Before the interview was carried out, the respondent was briefed about the aim of the survey and assured that all of the information given would be kept confidential. A consent form was provided on request. With the completion of the questionnaire, a HK\$50 supermarket coupon was given as a token of appreciation. Each interview lasted for about an hour. The interviews were audiotaped and transcribed. Furthermore, participant observation was conducted to collect information on the setting of the service, 
contents of the program, behavior of the service users, and interaction between service users and staff members. I had different degrees of participation in these programs: I worked as a volunteer in the day-care and residential rehabilitation centers, but in the methadone clinic, I was merely an observer. As a result, different observational skills were applied in these settings: unobtrusive observation in the day-care and residential rehabilitation centers and reactive observation in the methadone clinic. The observations in these programs were immediately recorded into a notebook or after the activity. The protocol of this study was approved by the Survey and Behavioral Research Ethics Committee at The Chinese University of Hong Kong.

The data from the participant observations and interviews were entered into a qualitative software package, ATLAS.ti (ATLAS.ti Scientific Software Development GmbH, Berlin, Germany), for systematic coding, and the coding frame was based on the interview topics and the purpose of the participant observation. From the coding to the writing of this article, pseudonyms were used for people and places. The coded data were then analyzed by using the grounded-theory approach. By comparing the self-reported data from the interviews and observational data from the participant observation, recurring themes related to the pattern of treatment use were identified. In this article, three themes are discussed: ethnicity, religion, and regulative practices in the treatment program. All of these themes are found to be related to the cultural concept of "freedom."

\section{Findings}

\section{“There is no freedom": use of residential rehabilitation services in Hong Kong}

Most of the residential rehabilitation centers in Hong Kong use a religious approach in drug treatment. Two of my informants expressed that they did not care for the programs because they were not religious and had no interest in the Christian practice. One of them commented that the program was "brain-washing" because service users were required to follow Christian practices from day to night. Comparatively, two of my informants expressed that they found the program to be helpful. One of them said that the program has helped him to "find the meaning of life" and "build correct moral values."

Other than religious reasons, five of my informants expressed that their reluctance to enter or stay in the program was because of the "cultural differences." They compared their experiences of using residential rehabilitation services in Nepal with those in Hong Kong and reported the following differences, respectively: treatment program (Narcotics Anonymous approach versus religious approach), ethnicity of staff members (Nepalis versus Chinese), duration (3-month in-residence program, followed by optional 3-month outresidence program versus 1 year in-residence program), food served in program (Nepali food versus Chinese food), and facilities (standard versus rudimentary).

However, as many as 12 of the informants suggested that religion and the above-mentioned cultural differences were less significant in their decision making about treatment use than the "human rights" issue. In the interviews, they often commented that they experienced "no human rights" when they received the services. Here are the accounts of three of my informants who described their experiences with "no human rights."

Sita is a 31-year-old woman who had used heroin for 5 years. She left for Hong Kong in 1996. Her boyfriend was also a heroin user, and in June 2010, he was arrested by the police and sent to prison. As she had lost her sole financial and emotional support, she decided to undergo the residential rehabilitation program in Hong Kong. She first visited a day-care center that provided referral services specifically for South Asian drug users. The day-care center is located in the Nepali community. I visited the center with her. We were first invited to sit in a small room, where a female Hong Kong Chinese social worker and a male Nepali assistant, who were both younger than Sita, conducted an interview with her. In the interview, the social worker asked Sita many personal questions, such as her family background and drug use history.

In the beginning of the interview, Sita was cooperative. However, later on, she became impatient and refused to answer the questions or just gave an unclear response. For instance, she was asked to draw her family tree. Sita only provided information about her parents. Then the social worker asked her whether she had any siblings. Sita said that she had five elder brothers. Then she was asked to give information about her brothers and their spouses and children. Sita felt annoyed. Furthermore, she was asked about her drug use history. She thought that she only needed to give information about her recent drug use. However, the social worker asked about her experience from her first to the latest drug use, including the amount, frequency, route of administration, location, price, with whom, and so on. After that, she was asked for the reason that she took drugs. She found this question to be funny and laughed. The social worker was not pleased. Then Sita said, "For fun." However, the social worker was unconvinced and earnestly told her that she had to tell the truth. Otherwise, she 
might not be able to find a suitable service for her. So Sita gave a more "honest" answer: loneliness. In the interview, the social worker spoke in English. At the beginning, Sita also replied to her in English. Yet because of the different accents, the social worker could not understand her answers. Therefore, Sita replied in Nepali and the Nepali assistant interpreted her words. Sita felt rather uneasy when she heard the interpretation, as she had to listen to her own drug use story, which was filled with many unhappy experiences. The interview lasted for 1.5 hours. After the interview, the social worker told Sita that she would inform her about the result in the coming few days. However, after leaving the center, Sita told me that she would not consider going to the rehabilitation center. She said, "Their rules are strict. I don't want to lose my freedom."

Nusan is a 20-year-old ex-heroin user. He left for Hong Kong in 2007 but had started to take heroin in 2003 in Nepal. Before he went to Hong Kong, he stopped using heroin for half a year. After arriving in Hong Kong, he resumed his heroin use. After 3 years, he decided to receive drug treatment at a rehabilitation center. When Nusan joined the rehabilitation center on the first day, I was also there. When he arrived, all the residents, including me, went to welcome him. We first sang a welcoming song to him. Then he was brought into an office for registration purposes. A Chinese staff member searched his body and his belongings to ensure that he had not brought any prohibited articles, such as illicit drugs, with him. After that, a senior Nepali resident shaved his head. Nusan originally had a spiky hairstyle. Within a few minutes, all of his hair was gone. The staff member took a picture of him before and after the haircut. In both pictures, Nusan showed no facial expression. When he saw his bald head in the mirror, he shook his head. Then he went to take a bath. When he came back from the bathroom, he was naked. All the residents could see his naked body. Then he was given some clothes and a towel.

In the first week, he stayed in a separate room. The Nepali residents took turns caring for him as he overcame his withdrawal symptoms. After a week, he joined the rest of the residents and followed the routine of the center, which included 1 hour of religious worship, 2 hours of Bible reading, and 3 hours of work (such as repairing the rooftop, painting the walls, making furniture, and cutting grass). I visited him 2 weeks later. He had been given a Christian name and looked healthier. Yet he told me that he was planning to leave. He explained to me: "I don't like the Chinese staff! One of them called me a beggar! He said I'll relapse [into heroin use] and become a street beggar if I don't change my attitude! I pretended that I did not understand him. Then he asked the other [Nepali] brothers if I have mental problems! He thinks that I am crazy! It's insulting!"

One week later, Nusan stopped the treatment. He said that he could not adapt to the program. He went back to Nepal and continued treatment at a rehabilitation center in Kathmandu.

Manju is a 28-year-old ex-heroin user. She arrived in Hong Kong in 2000 and started to take heroin in 2002. She took part in a residential rehabilitation program twice in Nepal but failed to abstain from heroin in both attempts. She lost the support of her family. In 2010, she decided to undergo treatment at a rehabilitation center in Hong Kong. She participated in the program for almost 1 year. She stopped just as she was about to finish the program. She explained to me that at the time, she hoped that the staff could assist her in finding a job so that she could live on her own after completing the program. Yet the staff turned down her request. In fact, the rehabilitation center was affiliated with a Christian denomination that believes in prophecies. From the prophecy, the staff explained to her that she needed a husband, rather than a job. They thus arranged a marriage for her to a Chinese ex-heroin user who was also about to complete the program. She did not like the idea and rejected their arrangement. After that, she felt that the staff were indifferent to her. She could not tolerate their attitude and terminated the treatment.

In these three cases, all of my informants had negative experiences during the services and felt that there were "no human rights." In fact, human rights are a broad concept condensed with multiple meanings, such as political, civil, socioeconomic, and cultural rights and so on. ${ }^{55}$ To better understand the informants' interpretation of "no human rights," it is important to understand their opinion of other drug-related services in Hong Kong, such as methadone services.

\section{"The service is free": use of methadone service in Hong Kong}

Since 1972, methadone clinics have been established throughout the territory. Patients only have to register with their identity card and pay HK\$1 for a dose of methadone each time. Since the 1990s, the clinics have also provided peercounseling programs and counseling services for patients. From the perspective of public health, many researchers have shown that the methadone program is effective in containing HIV: the HIV prevalence has remained low (less than 1\%) among injection heroin users in Hong Kong. ${ }^{3-5}$

Among my informants, four of them mentioned problems with the methadone service in Hong Kong. They said that 
the service led them to a "double addiction": being addicted to heroin and methadone at the same time. In addition, they became even sicker when they underwent the detoxification programs. Sanjeev had the experience of going to a rehabilitation center both before and after taking methadone. Before he took methadone, the nausea during detoxification was intense but lasted for no more than 3-4 days. After taking methadone, the sickness was slightly less intense but lasted for more than 1 week. This belief is commonly held by many Nepali drug users. For some of them, who have used methadone, this became the reason for them to not undergo rehabilitation services.

Despite the above-mentioned problems, all of my informants agreed that the methadone service in Hong Kong is good. The most commonly claimed reason was that the service is almost "free." It only costs HK\$1. Furthermore, this service is free of "supervision." Sita, who had the experience of using both the referral services in a day-care center and the methadone service, said, "The methadone service is good. It is convenient." When I carried out participant observation in one of the methadone clinics that was often visited by Nepali heroin users, I found three features in the clinic that made the service "convenient" to them: location, procedure, and setting.

First, the methadone clinic is geographically located at the boundary of the Nepali community, in an alley between two main roads that have high pedestrian and traffic flow. Very few people or vehicles would go into the alley, which protects the service users from the public gaze. Second, the procedures of using the service are simple: users only have to show their identity card and pay HK\$1. Then the users can drink the methadone and leave the clinic. When the clinic opened in the afternoon, people might have to line up and wait, but it would not take too long. In most of the cases, it took no more than 5 minutes to use the service. Third, the setting in the clinic limits social interactions. The clinic is divided into private and public areas. In the clinic, there is a security guard, social worker, peer counselor, administrative officer, and two medical officers. The administrative and medical officers work in the private area. The administrative officer is responsible for checking the identity card of the service users and collecting the dollar from them; the medical officers are responsible for prescribing methadone to the users. The administrative officer works behind a wall partition with a very small window, and his/her face is obscured. The medical officers work behind a window partition. They wear a face mask, gloves, and hospital gown. They barely talk to the users. On the basis of previous records, they prescribe the same amount of methadone to the users. Sometimes, the users would make a request to change the amount. Then the officer would increase or decrease the amount by $5 \mathrm{~mL}$.

The social worker, security guard, and peer counselor work in the public area. The security guard is a middle-aged Chinese woman. Her duty is to maintain order at the clinic. She would use simple Chinese phrases and hand gestures to remind the service users to line up properly, lower their voices when they talked, and ask the users to leave the clinic after using the service. There are two social workers, one male and one female. They attend the office on alternate days. While they are on duty, they usually meet clients in their office. When they have no clients, they stand outside their office and observe the service users. They seldom take the initiative to approach the users, as they explained to me that the counseling service is optional. The peer counselors are Nepali and current heroin users. They are employed by the social worker to introduce the peer-counseling programs to the Nepali service users. However, they seldom take the initiative to introduce the service, as they seldom themselves attend the program and have mainly taken this job because of the hourly salary. In the clinic, there are benches, but nobody would sit on them. I was the only one; in fact, I had to seek approval from the authority to allow me to stay there and carry out observation. Once I saw a Nepali friend at the clinic and chatted with him on the bench. However, the security guard came up to us and asked us to lower our voices. In fact, our voices were very low. The warning implied that we should stop our conversation. Even though the clinic has a high flow of service users, it is maintained as a very quiet and orderly place. There is minimal conversation. After drinking the methadone, everyone would immediately leave. I asked the social worker why there is such a high level of formality in the clinic. She explained to me that methadone is a controlled medication and that greater precaution has to be taken to prevent smuggling. Despite this high degree of formality, all my informants agreed that the methadone service in Hong Kong is good and stressed that it is "free" and "convenient." In the next section, I analyze the cultural meanings of these comments.

\section{Discussion}

This research has a number of limitations. First, this research is largely based on ethnographic and qualitative data. More quantitative research is needed to verify the argument and determine how the social variables of Nepali drug users, such as sex and class/caste, would affect their treatment use. Second, all of the informants were recruited by purposive 
and snowball sampling, and ethnography was mainly carried out in three locations. The findings are thus limited by the social network of my key informants and the geographic location. The findings are unlikely to reflect the views and experiences of Nepali heroin users in Hong Kong who are receiving treatment in other locations. Third, I have not systematically discussed the pattern of treatment use of my informants from initiation, through continuation, to cessation. Instead, I focused on their subjectivity: how they viewed the drug-related services in Hong Kong and thus justified their usage at the time of the interviews. Therefore, I cannot claim to have thoroughly studied the pattern of treatment use of my informants, but only the aspects that my informants found to be significant to them.

Despite these limitations, the findings in this research should contribute to a better understanding of the relationship between ethnicity and pattern of treatment use. Nepal is a developing country, and the provision of social services is limited. All my informants agreed that access to drug-related services in Nepal is not as easy as it is in Hong Kong. For instance, methadone services in Nepal are a high-threshold program run by the government that targets drug abusers who are poor, have a long history of drug abuse, and abuse drugs by injection, whereas residential rehabilitation services are paid services run by nongovernmental organizations that target drug users who are from middle-class families. In contrast, most drug-related services in Hong Kong are free or low in cost, and drug users, regardless of class and ethnicity, can have access to the services. Thus, when my informants commented that there are "no human rights" in drug-related services in Hong Kong, it is unlikely that they were referring to civil rights, having equal access to appropriate social services and medical treatment. On the contrary, it is more likely that they were referring to cultural rights: the ensuring of one's cultural tradition.

With regard to residential rehabilitation services, seven of the informants complained about the religious approach and the cultural differences, such as food, religion, facilities, and the ethnicity of the staff. However, most of my informants did not find these differences to be significant problems. In fact, most Nepalis in Hong Kong are the descendants of Gurkha soldiers. Under the British influence, they are constructed as the "martial race." ${ }^{56}$ Because of British colonization, they migrated to Hong Kong, where the image of the "martial race" is largely preserved. In the cultural beliefs of a "martial race," the martial quality is passed down from the forefathers, who lived in difficult environments, such as the hill regions, a "pure" terrain in Nepal.
When the new generation grows up in the city, and not a difficult environment, they would lose their martial qualities and become prone to deviant behavior, such as drug use. To prevent this, the parents may arrange for their children to live in a difficult environment, such as their hometown, a rural village in the hill regions, for a period of time, which would revive their martial qualities. In other words, living in a difficult environment is a beneficial arrangement to the new generation of the "martial race." Furthermore, the obeying of foreign authority is also defined as one of the characteristics of the "marital race." In the British Army, the Gurkhas are famous for being loyal to the British officers. Many of my informants in the interviews identified themselves as the "martial race" and agreed to the qualities described here. This explains why few of my informants complained about the poor conditions or foreign authority in the rehabilitation centers. In their perspective, the problem of residential rehabilitation services comprises other factors.

Many studies have shown that caste is an important factor in the social life of Gurkhas. Many of the caste traditions of Indian indentured migrants in South Africa, Trinidad, and Fiji have already been lost because their migration was not caste-based and caste traditions were not encouraged in the host society. ${ }^{27}$ Comparatively, the British Army allows the Gurkhas to preserve their caste traditions, especially the caste divisions. ${ }^{56,57}$ This tradition continues after their retirement and migration to a new society, such as Hong Kong. ${ }^{58}$ Gurkhas are composed of several ethnic groups. In the caste system in Nepal, they belong to the middle caste. Each ethnic group has its own subcaste system. However, during my participant observation, I found that most Hong Kong people assume that Nepalis in Hong Kong belong to a homogenous group; that all of them are Gurkhas. In fact, some of the non-Gurkhas, such as low-caste Nepalis, also live in Hong Kong. They are often called fake lahures (Gurkha in Nepali) by the Gurkhas, as they usually enter Hong Kong through false means, such as through a "paper marriage" or the use of a fake ID. Compared with the real lahures, they have a lower socioeconomic status in Hong Kong. When they become drug users, they are more likely to live on the streets, and their choice of drug is usually cough syrup, rather than heroin, as heroin is too expensive. However, in Hong Kong, heroin is usually consumed by "older, lower and working-class males," or individuals who are unemployed and have low levels of education. ${ }^{59,60}$ The Chinese staff at the rehabilitation center often assumed that the Nepali heroin users in Hong Kong also shared the same socioeconomic status, and this belief was sometimes confirmed by the low-caste Nepali drug users who received 
treatment in the rehabilitation center. However, many of the Nepali drug users in Hong Kong have a good education and middle-class family background. When they were compared with low-caste Nepalis, they felt it was strongly culturally inappropriate. In Nusan's case, he did not find that the boot camp-style tactics and intimidation in the rehabilitation center to be problematic, as these are also commonly practiced in rehabilitation centers in Nepal. Among my informants, only a few of them complained about these tactics. Thus, the problem lies in other factors; for instance, the difference in sociocultural context.

In Nepal, most of the residents in the rehabilitation centers belong to the middle caste, whereas in Hong Kong, the Nepali residents include those from different castes. When a resident is intimidated in front of other residents who share a similar status, it is less humiliating. Comparatively, when a resident, such as Nusan, who has a higher status (Nusan's father served in the British Army, and his family legally migrated to Hong Kong), is intimidated in front of other residents who share different statuses and is compared with residents who have lower statuses (he was described by the Chinese staff as a "beggar" and "mentally retarded," and in his belief, only lower-caste Nepali drug users would live on the streets [be beggars] and have mental problems [the effect of overuse of cough syrup]), it is more humiliating.

Other than caste, sex is also an important factor in the social life of Gurkhas. There is a clear hierarchy between men and women, as migration is often initiated by the husband, and the wife only plays the role of a trailing spouse. In the life career of female Gurkhas, they are to observe chastity and modesty, maintain a good reputation (ijat), marry a husband who serves in the British Army or holds a foreign passport, and migrate overseas to support the husband and care for the family. ${ }^{45}$ In the Nepali culture, drug use is associated with risk-taking, adventure, and aggressiveness and is seen as a masculine activity; there is a social taboo against women taking drugs. ${ }^{61}$ Compared with male drug users, female drug users occupy a very marginal position in the Nepali community. They have to hide their drug activity very carefully. Yet female drug users who are younger, are the daughter of an ex-Gurkha, and have the opportunity to step-migrate to Britain to start a new life may not follow these sex-biased traditions. Both Sita and Manju are middleaged women who have scant opportunity to step-migrate to Britain; therefore, they strongly believed that maintaining a good reputation in Hong Kong was very important. They criticized the fact that the day-care and rehabilitation centers violated their human rights. It seems that these services had interfered with their personal life. However, the drug-related services in Hong Kong are not the only ones that emphasize integrative services (those services that involve the family of service users): the drug-related services in Nepal also use the same approach. It is not uncommon for the staff at rehabilitation centers to liaise with the family of service users and to arrange marriages for them after treatment, as they believe a married person would become more responsible and less likely to relapse into drug use. Thus, the problem lies in the means, not the ends, of these practices. For instance, Sita felt it was culturally inappropriate to share her story in front of a male Nepali, as this strongly undermined her reputation. Similarly, Manju felt it was culturally inappropriate to marry a man arranged by the staff at the rehabilitation center, as he was Chinese and an ex-heroin user who had a very low socioeconomic status. His social characteristics did not accord with her expectations.

Compared with the day-care and residential rehabilitation services, methadone services in Hong Kong follow a biomedical model, which places emphasis on the physical health of patients. The counseling service at the mentioned clinic is optional. With such an arrangement, service users could receive the service without any contact from the staff. From the perspective of the Nepali service users, this could largely reduce the risk of being demeaned or culturally offended by the staff in social interactions. Even though there are regulative practices, such as urinalysis and restrictive onsite doses, these practices did not deter my informants from using the service. From their perspective, these practices can keep the service highly formal and prevent the staff from interfering with their life beyond their physical body. Without these constraints, many of my informants agreed that methadone was an effective means of controlling their heroin dependence. Thus, when my informants described the methadone service as free and convenient, they not only meant that the service was low in cost and highly efficient but also that it was "free" of the risk of losing cultural capital. Unlike with the day-care or residential rehabilitation services, the informants did not need to face the risk of losing their cultural capital, such as honor and reputation, in exchange for the methadone service.

\section{Conclusion}

This article explores the views of Nepali heroin users on drug-related services in Hong Kong and the reasons that they have a relatively high usage rate of methadone services, but a relatively low usage rate of day-care and residential rehabilitation services. On the basis of data from ethnographic fieldwork and interviews, it is found that this might be related to the treatment approach and cultural 
conflicts, or in their own words, the experience of "no human rights." Even though drug-related services in Hong Kong tend to be culture-specific, such as employing South Asian workers and specifically arranging services for South Asians, many Nepali service users still find that the services are not suitable for them. The problem lies in the cultural perception of service providers of Nepalis in Hong Kong: they assume that Nepalis in Hong Kong are a homogenous group and overlook the social variables, such as sex and class/caste, that significantly differentiate the members in the community. These conflicts more commonly occur in integrated services than in services that use a biomedical approach, as service users and the staff tend to have more social interactions in the former.

Compared with other studies on faith-based rehabilitation programs, this research agrees with the argument that faith-based programs are more effective for service users who have a high level of spirituality/religiosity. Furthermore, this research finds that these service users seldom report problems when they have to switch from spirituality-based treatment (eg, Narcotics Anonymous in Nepal) to religiosity-based treatment (eg, Christian approach in Hong Kong) or follow the practices of other religions. However, this research also finds that faith-based programs might become less effective for these service users when cultural conflicts arise because of ethnic differences. With regard to studies on methadone services, this research finds that regulative practices are not necessarily viewed as barriers to the services from the perspective of the service users. When there are cultural conflicts between service providers and service users, these regulative practices might be viewed as protective measures for the latter, preventing them from being culturally exploited. Finally, this research sheds light on the arguments in drug treatment studies. Ethnicity is a significant factor in drug treatment, especially when the service providers have little cultural understanding of the service users, and at the same time, there is intensive cultural contact between them. Under such circumstances, culture-specific measures that take the treatment approach and social and cultural characteristics of the clients into consideration should be adopted to cater to the needs of different ethnic groups.

\section{Acknowledgment}

This study was completed with the support of the Beat Drugs Fund, Narcotics Division, Hong Kong. The author gratefully acknowledges their support.

\section{Disclosure}

The author reports no conflicts of interest in this work.

\section{References}

1. Narcotics Division (HK). CRDA and drug statistics. Major ethnic group. Available from: http://www.nd.gov.hk/en/statistics_list.htm/.Accessed 8 July, 2013.

2. Cheung YW, Ch'ien JM. Drug use and drug policy in Hong Kong: changing patterns and new challenges. Subst Use Misuse. 1996; 31(11-12):1573-1597.

3. Chan MK, Lee SS. Can the low HIV prevalence in Hong Kong be maintained? AIDS Educ Prev. 2004;16(3 Suppl A):18-26.

4. Lee PFI. ACAN in the 21st Century: A Continuing Challenge. Hong Kong: Narcotics Division, Action Committe Against Narcotics; 2001.

5. Lee SS. A humble service that has delivered public health good. Public Health. 2007;121(11):884-886.

6. Chen CN, Lee TS, Leung TYS, Wing YK, Lee S. An Evaluation Study of the Non-Subvented Voluntary Drug Treatment and Rehabilitation Agencies in Hong Kong. Consulting Report to Social Welfare Department, Hong Kong Special Administration Region Government. Hong Kong: The Chinese University of Hong Kong; 1997.

7. Tam SM, Tang WM. Transnationalism and Drug Abuse: A Study on Nepalese Drug Abusers in Hong Kong. Research report. Hong Kong: Narcotics Division of Hong Kong; 2011. Available from: http://www. nd.gov.hk/pdf/TDUreport_Full.pdf. Accessed February 3, 2012.

8. Galanter M. Spirituality and recovery in 12-step programs: an empirical model. J Subst Abuse Treat. 2007;33(3):265-272.

9. Pardini DA, Plante TG, Sherman A, Stump JE. Religious faith and spirituality in substance abuse recovery: determining the mental health benefits. J Subst Abuse Treat. 2000;19(4):347-354.

10. van der Meer Sanchez Z, Nappo SA. Religious treatments for drug addiction: an exploratory study in Brazil. Soc Sci Med. 2008;67(4): 638-646.

11. Arnold R, Avants SK, Margolin A, Marcotte D. Patient attitudes concerning the inclusion of spirituality into addiction treatment. J Subst Abuse Treat. 2002;23(4):319-326.

12. Christo G, Franey C. Drug users' spiritual beliefs, locus of control and the disease concept in relation to Narcotics Anonymous attendance and six-month outcomes. Drug Alcohol Depend. 1995;38(1):51-56.

13. Murray TS, Malcarne VL, Goggin K. Alcohol-related God/higher power control beliefs, locus of control, and recovery within the Alcoholics Anonymous paradigm. Alcohol Treat Q. 2003;21:23-39.

14. Miller WR, Forcehimes A, O'Leary MJ, LaNoue MD. Spiritual direction in addiction treatment: two clinical trials. J Subst Abuse Treat. 2008;35(4):434-442.

15. Galanter M, Dermatis H, Bunt G, Williams C, Trujillo M, Steinke P. Assessment of spirituality and its relevance to addiction treatment. J Subst Abuse Treat. 2007;33(3):257-264.

16. Lillis J, Gifford E, Humphreys K, Moos R. Assessing spirituality/ religiosity in the treatment environment: the Treatment Spirituality/ Religiosity Scale. J Subst Abuse Treat. 2008;35(4):427-433.

17. Atkins RG Jr, Hawdon JE. Religiosity and participation in mutual-aid support groups for addiction. J Subst Abuse Treat. 2007;33(3):321-331.

18. Dermatis H, Guschwan MT, Galanter M, Bunt G. Orientation toward spirituality and self-help approaches in the therapeutic community. J Addict Dis. 2004;23(1):39-54.

19. Bruce RD. Methadone as HIV prevention: high volume methadone sites to decrease HIV incidence rates in resource limited settings. Int J Drug Policy. 2010;21(2):122-124.

20. Neale J. Opioid pharmacotherapy: Treatment, regimes, constructions and control. Int J Drug Policy. 2013;24(6):e1-e5.

21. Chandler A, Whittaker A, Cunningham-Burley S, Williams N, McGorm K, Mathews G. Substance, structure and stigma: parents in the UK accounting for opioid substitution therapy during the antenatal and postnatal periods. Int J Drug Policy. 2013;24(6):e35-e42.

22. Crawford S. Shouting through bullet-proof glass: some reflections on pharmacotherapy provision in one Australian clinic. Int J Drug Policy. 2013;24(6):e14-e17.

23. Harris M, Rhodes T. Methadone diversion as a protective strategy: the harm reduction potential of 'generous constraints'. Int J Drug Policy. 2013;24(6):e43-e50. 
24. Strike C, Millson M, Hopkins S, Smith C. What is low threshold methadone maintenance treatment? Int J Drug Policy. 2013;24(6): e51-e56.

25. Treloar C, Valentine K. Examining structural violence in opioid pharmacotherapy treatment in Australia: sweating the "small stuff" in a liberal paradise. Int J Drug Policy. 2013;24(6):e11-e13.

26. Monaghan M, Wincup E. Work and the journey to recovery: exploring the implications of welfare reform for methadone maintenance clients. Int J Drug Policy. 2013;24(6):e81-e86.

27. Wu LT, Pan JJ, Blazer DG, Tai B, Stitzer ML, Woody GE. Using a latent variable approach to inform gender and racial/ethnic differences in cocaine dependence: a National Drug Abuse Treatment Clinical Trials Network study. J Subst Abuse Treat. 2010;38 Suppl 1:S70-S79.

28. Maddux JF, Desmond DP. Ethnic matching of caseworker and patient in methadone maintenance. J Subst Abuse Treat. 1996;13(3): 233-239.

29. Becker SJ, Stein GL, Curry JF, Hersh J. Ethnic differences among substance-abusing adolescents in a treatment dissemination project. J Subst Abuse Treat. 2012;42(3):328-336.

30. Jerrell JM, Wilson JL. Ethnic differences in the treatment of dual mental and substance disorders. A preliminary analysis. J Subst Abuse Treat. 1997;14(2):133-140.

31. Lundgren LM, Amodeo M, Ferguson F, Davis K. Racial and ethnic differences in drug treatment entry of injection drug users in Massachusetts. J Subst Abuse Treat. 2001;21(3):145-153.

32. Fosados R, Evans E, Hser YI. Ethnic differences in utilization of drug treatment services and outcomes among Proposition 36 offenders in California. J Subst Abuse Treat. 2007;33(4):391-399.

33. Yu J, Clark LP, Chandra L, Dias A, Lai TF. Reducing cultural barriers to substance abuse treatment among Asian Americans: a case study in New York City. J Subst Abuse Treat. 2009;37(4):398-406.

34. Feaster DJ, Robbins MS, Henderson C, et al. Equivalence of family functioning and externalizing behaviors in adolescent substance users of different race/ethnicity. J Subst Abuse Treat. 2010;38 Suppl 1: S113-S124.

35. Kosten TR, Rayford BS. Effects of ethnicity on low-dose opiate stabilization. J Subst Abuse Treat. 1995;12(2):111-116.

36. Bart G, Wang Q, Hodges JS, Nolan C, Carlson G. Superior methadone treatment outcome in Hmong compared with non-Hmong patients. J Subst Abuse Treat. 2012;43(3):269-275.

37. Clair M, Stein LA, Soenksen S, Martin RA, Lebeau R, Golembeske C. Ethnicity as a moderator of motivational interviewing for incarcerated adolescents after release. J Subst Abuse Treat. 2013;45(4):370-375.

38. Bohra-Mishra P. Nepalese migrants in the United States of America: Perspectives on their exodus, assimilation pattern and commitment to Nepal. J Ethn Migr Stud. 2011;37(9):1527-1537.

39. Nath L. Migration, insecurity and identity: The Nepali dairymen in India's Northeast. Asian Ethn. 2006;7(2):129-148.

40. Pariyar M. Cast(e) in Bone: The Perpetuation of Social Hierarchy among Nepalis in Britain. Working Paper no 85, Center on Migration, Policy and Society, University of Oxford; 2011. Available from: https:// www.compas.ox.ac.uk/fileadmin/files/Publications/working_papers/ WP_2011/WP1185\%20Pariyar.pdf. Accessed August 4, 2011.

41. Sharma JR. Practices of male labor migration from the hills of Nepal to India in development discourses: Which pathology? Gender Dev Technol. 2008;12(3):303-323.

42. Sharma JR. Marginal but modern: Young Nepali labour migrants in India. Young. 2013;21(4):347-362.

Substance Abuse and Rehabilitation

\section{Publish your work in this journal}

Substance Abuse and Rehabilitation is an international, peer-reviewed, open access journal publishing original research, case reports, editorials, reviews and commentaries on all areas of addiction and substance abuse and options for treatment and rehabilitation. The manuscript management system is completely online and includes a very quick and fair
43. Uesugi T. Re-examining transnationalism from below and transnationalism from above: British Gurkhas' life strategies and the Brigade of Gurkhas' employment policies. In: Ishii H, Gellner DN, Nawa K, editors. Nepalis Inside and Outside Nepal. New Delhi: Manohar Publishers and Distributors; 2007:383-410.

44. Yamanaka K. Nepalese labour migration to Japan: From global warriors to global workers. Ethnic Racial Stud. 2000;23(1):62-93.

45. Yamanaka K. Changing family structures of Nepalese transmigrants in Japan: Split-households and dual-wage earners. Global Netw. 2005;5(4):337-358

46. Dhital R, Subedi G, Gurung YB, Hamal P. Alcohol and Drug Use in Nepal: With Reference to Children. Kathmandu: Child Workers in Nepal Concerned Centre; 2001. Available from: http://www.cwin.org.np/resources/ cwin-publications/occasional-publications. Accessed August 6, 2013.

47. Fisher J. Cannabis in Nepal: An overview. In: Rubin V, editor. Cannabis and Culture. The Hague: Mouton; 1975:247-255.

48. Jutkowitz JM, Spielmann H, Koehler U, Lohani J, Pande A. Drug use in Nepal: the view from the street. Subst Use Misuse. 1997;32(7-8): 987-1004.

49. Shrestha NM. Alcohol and drug abuse in Nepal. Br J Addict. 1992;87(9): 1241-1248.

50. Bhandari B. Status of drug abuse and its prevention: from United Nations to Nepal. In: Bhandari B, Sarmah HP, editors. Drug Abuse in Nepal: Prevalence, Prevention, Treatment, and Rehabilitation. Kathmandu: Drug Abuse Prevention Association Nepal; 1988:1-46.

51. Bhandari R. Some social causes of drug addiction in Kathmandu. In: Bhandari B, Sarmah HP, editors. Drug Abuse in Nepal: Prevalence, Prevention, Treatment, and Rehabilitation. Kathmandu: Drug Abuse Prevention Association Nepal; 1988:158-168.

52. Subba C. Drug and drug addiction in Nepal. In: Bhandari B, Sarmah HP, editors. Drug Abuse in Nepal: Prevalence, Prevention, Treatment, and Rehabilitation. Kathmandu: Drug Abuse Prevention Association Nepal; 1988:47-72.

53. Gafney T. The root causes of Nepali drug delinquency: Behavioural and adjustment disorders. In: Bhandari B, Sarmah HP, editors. Drug Abuse in Nepal: Prevalence, Prevention, Treatment, and Rehabilitation. Kathmandu: Drug Abuse Prevention Association Nepal; 1988:135-145.

54. Subba K. Drug users of Dharan: Aspects of marginalization. In: Ishii H, Gellner DN, Nawa K, editors. Nepalis Inside and Outside Nepal. New Delhi: Manohar Publishers and Distributors; 2007:283-306.

55. Messer E. Anthropology and human rights. Annu Rev Anthropol. $1993 ; 22: 221-249$

56. Caplan L. Warrior Gentleman: “Gurkhas” in the Western Imagination. Providence: Berghahn Books; 1995.

57. Des Chene M. Relics of Empire: A Cultural History of the Gurkhas, 1815-1987 [dissertation]. Stanford: Stanford University; 1991.

58. Tang WM. Transnational migration and heroin use among children of ex-Gurkha soldiers in Hong Kong. Stud Nepali His Soc. In press 2013.

59. Joe Laidler KA. The rise of club drugs in a heroin society: the case of Hong Kong. Subst Use Misuse. In press 2014.

60. Lee SS, Pang TT. Integrated assessment of addiction epidemiology in Hong Kong 1996-2005. In: Thomas YF, Richardson D, Cheung I, editors. Geography and Drug Addiction. Dordrecht: Springer Science and Business Media BV; 2008:131-144.

61. Sinha A. Exploring the social dimensions of drug abuse and service interventions in Nepal. Stud Nepali His Soc. 2008;13(1):71-115.

\section{Dovepress}

peer-review system. Visit http://www.dovepress.com/testimonials.php to read real quotes from published authors. 